\title{
EL LABERINTO Y LA PARADOJA EN LA POESÍA DE \\ JUAN CALZADILLA
}

\author{
POR \\ LuBio CARDozo
}

... La hazaña consiste en no dejar de ser el mismo. Esto sí es raro.

Juan Calzadilla.

No sé si resulta prematuro hablar en este momento —por la relativa cercanía, 1993de una generación de los años sesenta, pero innegablemente a la importancia histórica de esa década hubo también una interpretación y una respuesta artística, literaria, a la altura de los acontecimientos. Y entre esos intelectuales hay una figura de relieve en el campo de la poesía, Juan Calzadilla. Con un haber de más de quince títulos aportadores, interesantes y originalísimos en este aspecto de su creación, no se puede dudar entonces de la hondura de su huella literaria, de sus testimonio, de su contestación al reto de la circunstancia de esa época. Moldeado por ese tiempo tan complejo, tan lleno de frustración política ciudadana, de tragedias políticas individuales y de una tremenda manipulación colectiva del venezolano desde las instituciones gobernantes, la poesía de Calzadilla torna esta complejidad en símbolos a los cuales le impone su personal sello y con ellos convertidos en hebras mágicas cose y construye su rica y peculiar obra literaria: el laberinto y la paradoja. Puede mediante estos dos recursos imaginativos el poeta captar el impacto trascendental de esa década en el espíritu de quienes la vivieron y la sobrevivieron. Aunque en el fondo, proveniente de dos perspectivas salidas del mundo real, parecieran significar lo mismo, el laberinto una paradoja del espacio y la paradoja un laberinto del lenguaje. Nacidos de lo inverosímil y lo absurdo de la realidad, adquieren categoría de símbolo, de lo verdadero en el lenguaje, mas portando consigo esa doble naturaleza de verdad y falsedad. Define el laberinto un camino mediante el cual se puede llegar o no, así como la paradoja una contradicción violente posee en su estructura, sin negarle hacia el final el descanso de una moraleja profunda, un agudo pensamiento cierto. ¿En la historia futura de Venezuela quedará una lección, una máxima divina al desenrollarse el laberinto o interpretarse las paradojas de los años sesenta? Por lo menos, para iluminar a su manera el mundo del espíritu, Calzadilla vertebró escalonadamente sus textos de poesía, tal vez ello sea su intención. A lo largo, pues, de su obra resaltan de manera particular estas dos ensambladuras, las cuales como, repito, hebras mágicas cruzan 
su inimitable lenguaje lírico, su personal castellamericano, enlazan sus palabras, fijan su prosa o su verso singular. En fin, estas dos construcciones permanentes soportan sobre su lenguaje múltiples aspectos dignos de destacar en la poesía de Calzadilla. Véanse cuáles son.

\section{II}

\section{Los años sesenta}

¿Cómo trasmuta Calzadilla en poesía el traumatismo espiritual de esa década? Recogen los años sesenta el resultado de la frustración política del 23 de enero, fecha con la cual nomínase el movimiento civil y militar insurgente contra la dictadura y cuando se pusieron tantas esperanzas para impulsar un rumbo nuevo, distinto a la vida durante los dos lustros del cincuenta y también antes de esos años. Un camino progresista y humano, inédito en la historia venezolana. Todo lo entramparon, sin embargo, los políticos profesionales quienes venían del exilio y no conocían al venezolano de esos años, tampoco habían participado en la gestación ni en la culminación de la revuelta de comienzos de 1958, pero sí, por el contrario habían protagonizado la vida política antes de 1950 y responsables indirectos del golpe de estado del entonces coronel Marcos Pérez Jiménez. En los sesenta de mil maneras se expresa esa derrota existencial, moral, política, económica de la sociedad venezolana, sobre todo más patética en su sector joven y pensante. Callejón sin salida, bloqueado y manipulado para el devenir de la historia nacional en esos años. Quedaba el destino político y económico (y por lo tanto social) de Venezuela pechado, sometido de manera vulgar a los intereses del capital llamado sofisticadamente multinacional, y sólo su ejecución pasaba cargo de los testaferros criollos, valga decir por los dos grandes partidos populistas del país. La mayoría de los jóvenes intelectuales nativos de una u otra manera en sus creaciones acusaron ese fracaso social. Uno de ellos, Juan Calzadilla, en sus primeros poemarios, interpreta, en un riguroso lenguaje lírico, el alma, la psique, del ciudadano víctima o cómplice de ese dolor existencial y social al través del poeta actuante en sus textos como testigo y a su vez voz para escribir el testimonio sacado de ese ver dentro de los hombres de ese tiempo. Tal constituye el impulso de libros como Dictado por la jauría (1962), Malos modales (1965) y Las contradicciones sobrenaturales (1967). En este último opúsculo el bardo presenta a la pequeña humanidad venezolana de esos lustros, subreal, cuya brújula ética e histórica había enloquecido y perdido el sentido de la transparencia (propia de una sociedad la cual hubiera podido ser estable y de alguna manera hermosa y sana). Por el contrario, salen en su texto hombres fragmentados por una derrota interior donde la paradoja - las contradicciones sobrenaturales - tórnanse su pan moral cotidiano,

Vives demasiado adentro y afuera de la ciudad para poder cumplir a cabalidad tu oficio de vivir. Oficio que desempeñas del mejor modo en lugar de otro y que te es impuesto desde dentro y de fuera de ti mismo para que de ningún modo puedas cumplirlo a cabalidad ("Tomas el pavimento por la forma exacta de tu piel"). 
No conozco ningún estudio psicoanalítico colectivo de la sociedad venezolana, o para ser menos ambicioso, por lo menos de Caracas, en la década de los sesenta. Necesitó Caracas en ese entonces una reflexión como urbe digna de acostarla en el sofá de una clínica psiquiátrica para examinarla por los excelentes médicos de aquel entonces como Mata de Gregorio, José Luis Vethencourt, entre otros. Pero su perfil psicótico sí lo hicieron, al través del diagnóstico de la estética, los jóvenes intelectuales, activos en la creación de ese tiempo, en cuyas obras - documentales, poemarios, cuentos, exposiciones de pintura y de fotografias, novelas, revistas - se plasmó la imagen espiritual dramática del país sesentero. La mágica enfermedad (1969) de Jesús Sanoja Hernández, las novelas de Salvador Garmendia de ese lapso, los mencionados poemarios de Calzadilla, las exposiciones del Techo de la Ballena ("Homenaje a la cursilería" en 1961, "Homenaje a la necrofilia", en 1962), los versos de Caupolicán Ovalles (En uso de razón, 1963; Elegía en rojo a la muerte de mi padre, 1967), los libros de Edmundo Aray (Twist presidencial, 1963); Sube para bajar, 1963), definen el rostro artístico: significante, de la faz real: significado, de ese período.

Encierra en sus páginas Las contradicciones sobrenaturales ese complejo, alienante, duro, difícil mundo de la década. La muerte como el sitio de ninguna posibilidad y la vida como la oportunidad única pero sacrificada al tedio, al vacío, como los manjares ofrecidos a Tántalo.

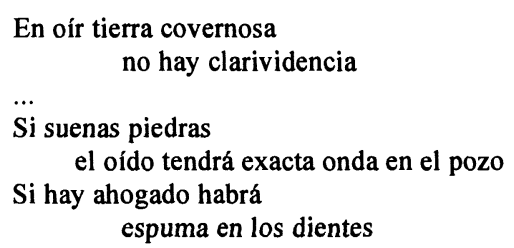

("Jaula para occisos")

¿Por qué dudar si la realidad eso enseña cotidianamente? En una sociedad enloquecida, manipulada, alimentada de subrealidad, en ciudades donde los seudovalores los implanta el consumismo, adquisición desaforada de objetos como espejos de la personalidad disminuida de ética, de ideología, de sentido humano, donde el significado raigal de patria pareciera haberse quedado en una mitología para llenar la rutina en las escuelas; el diálogo no existe, pero ni tan siquiera llegar al soliloquio sereno, puro. Conspira todo contra el silencio y el alma. Pareciera, pues, tener razón Lacan, la palabra revela su injusticia con el pensamiento, lo traiciona, luego el poeta en venganza la transforma en ludismo, logomaquia, señales apenas para estimular las emociones, la carne, y sobre el espíritu cuando se metamorfosea en el proyectil del poema.

El diálogo no se construye como una gradería por cuyos peldaños han de desplazarse rápidamente los vivos corriendo hacia los muertos. 


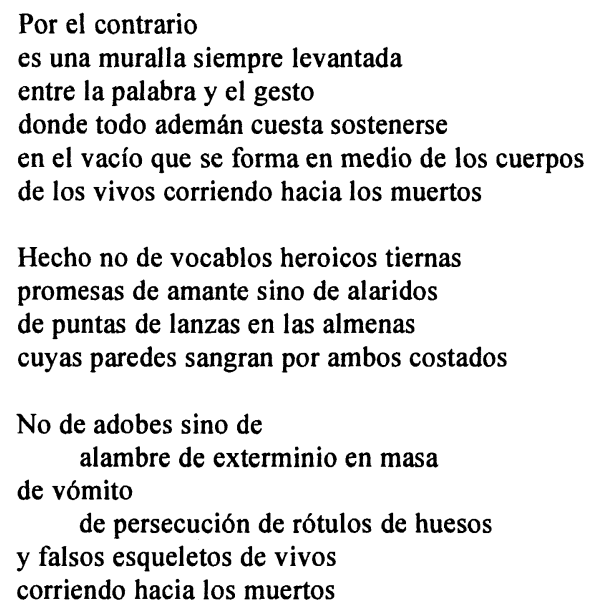

("Piedra sobre piedra")

\section{La ciudad}

En cierto modo el hombre hácese a la medida de su ambiente, de una u otra forma entabla con él relaciones de complicidad, el humano ejecuta el papel del espejo activo, no tanto reflectar sino asimilar lo exterior, y si hay reflejo éste buscará la vía de las actitudes, del comportamiento, de la manera de existir. Mas el entorno se ultracomplejiza cuando transfigúrase en caótica urbe. Su influencia sobre el hombre se concentra, el espacio se hace patético, nace allí ese ciudadano especial, ese ser cuya carne más exterior la define ella, la ciudad, un laberinto cotidiano, conocido y dominado mientras no enloquezca y autogenere una arquitectura devoradora de sí misma para el prolongado parto de su propia monstruosidad. Resulta el hombre entonces un cautivo del laberinto transformado ahora en un endriago. Este humano itinerante, reo de la enorme boa no constrictor sino de concreto, ladrillos cabillas, vidrios, postes, cables, se llamará a partir de ese momento "ciudadano sin fin" como bien lo nominó Juan Calzadilla, título con el cual bautizó su poemario de 1970 .

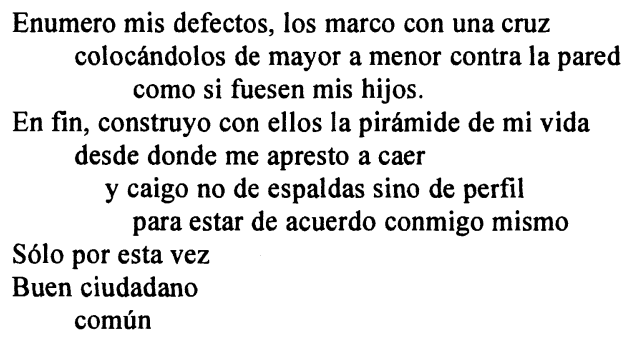


Juan Calzadilla quedó profundamente marcado en su psique por los años sesenta. Sintieron su nobleza y su juventud, a fuer de buen venezolano, correr sobre su alma la trilogía trágica de la traición política a los ideales del "23 de Enero", la respuesta de los mejores jóvenes venezolanos a lo anterior mediante la lucha armada, y luego la derrota de ésta bajo la represión militar y policial, las ordalías pavorosas y el aislamiento de las masas por la escandalosa propaganda oficial. Caerá sobre el laberinto moral y físico de Caracas la pertinaz lluvia del desaliento, la enajenación, un frenesí sin rumbo determinado y en la cual aparecerá como fruto de la locura cotidiana el ciudadano sin fin.

Ciudadano libre en esta ciudad no humana pero tampoco divina donde flota tan sólo por una décima de segundo y pudiendo esperar mucho más tiempo aún debajo de la tierra a una edad en que nada bueno promete el tiempo con olor a colmena fúnebre a sabiendas que conviene ser siempre el mismo y que no venimos únicamente para vivir y sin ningún país por el que exista momentáneamente la obligación o el deber de morir y pensando que algo va a suceder cuando ya nada ocurra junto al público que me hace perder el equilibiro en el instante más decisivo de mi número doy un paso en falso sobre la tierra accidentada que abre su sexo no tengo ni buenos ni malos antecedentes pido disculpa señores el bien y el mal cohabitan en cada partícula mía

(“Reo")

Ciudadano sin fin por lo demás revela un poemario rico en fuerza expresiva, vivencias, y esa curiosa capacidad de Calzadilla de concebir dentro de su lírica personajes con vida independiente, reflejos de esa circunstancia de la cual ya se ha hablado, a quienes el poeta les asigna la dolorosa responsabilidad de contar sus cuitas, su propia tragedia, la de ellos. Aunque editado en 1970 incorpora sin embargo algunos poemas de Las contradicciones sobrenaturales por cuanto ensamblan con el drama del libro.

\section{El extraño}

Como se dijo en párrafos anteriores la ciudad prolonga su meandro ya no hacia el espacio robado a la belleza exterior y natural sino lo introduce en el ciudadano sin fin; lo laberintiza a él también y lo cambia en un caos sin remedio lógico posible, sólo le resta la salida de la extrañidad, el ciudadano extraño hasta para sí mismo. El logro del descubrimiento del mundo del labertinto así como su recurso más afín para expresarlo, la paradoja, acóplanse para el soporte del poemario de Juan Calzadilla Manual de extraños, del año 1975. Ahora la ciudad, presente en todo momento, va detrás como telón de fondo del escenario y poetiza mediante un humor "gris" de muy buena ley,

Alrededor te tengo ciudad me tienes somos el uno en el otro la partida y el regreso fijos en el centro del camino el sol blanco que para reconciliarse graba signos cabalísticos en nuestras sienes el cordel negro que roe las bases de las alcantarillas el dado de la memoria que gira 


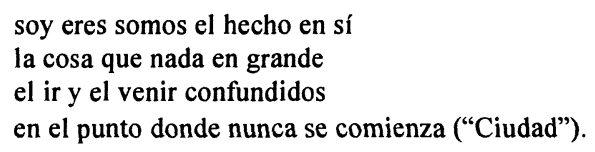

Delante de ella, en pleno escenario, los ciudadanos extraños perdidos en el laberinto interior donde extravíanse sin reconocerse definitivamente el yo, el cuerpo, la personalidad, el uno mismo. Y el poeta logra comunicar de manera magistral esta fragmentacíon del ego mediante el uso de la paradoja. Humor y antinomias donde lo lírico sobresale por la furza del lenguaje y la verroqueña autenticidad escritural de Calzadilla donde su modo de concebir el mundo, su sinceración se transmuta en poemas. ¡Cuidado! Autenticidad en la intensidad del lenguaje y en la escrituración del poema; desdoblamiento en la hechura de sus extraños ciudadanos quienes tejen y destejen las voces de los versos mientras se desorientan sin salvación en el doble dédalo del caotismo de la urbe y de su alma.

En la ciudad resuelvo llevar una máscara de latón.

Qué tal si, por el contrario, es una forma de quedar bien ante el público

que me rechaza con la rapidez de la flecha clavada en vano.

(“Máscara de Latón”)

Aquél que, de suyo, no es otra cosa que lo que le falta para obtener título de ciudadano común

que camina falto de cuerpo y cuya levitación necesita ser autorizada por los jueces

aquél cuya vida aún no se ha sido que entra siempre en el campo de las sospechas accionando manos que se presentan a ser confundidas con su pies

A Juan Calzadilla lo defino como un poeta excepcional, un intelectual cuya actividad inventiva total desemboca siempre en la poesía. Pintor interesante, sus signos plásticos aterrizan con frecuencia en las palabras, mas a la artisticidad de su vida agrégase la reflexion estética en profundidad ya sobre el arte plástico ya sobre la creatividad en general pero vinculado al través de su expresión, de su comunicación, con el poema como diálogo trascendente. El poema constituye su faz última, su señal - tal vez - más sólida sin restarle entereza y valía a toda su obra plástica y de investigación así como de crítica artística. En Manual de extraños por sobre la tragedia de la alienación del ciudadano 
sin fin reposa la belleza. Lo calológico sálvase y salva, además. De lo dicho he aquí un ejemplo, el poema "Profecías",

Los que sin ser reyes fueron coronados por las gotas de lluvia,

los que no suman cuando son numéricamente contados.

Los que arrojan alcohol a los pájaros en medio de una pesadilla,

los que muestran su eclipse privado en la arruga del ojo,

los que saben de la muerte por haber oído algo acerca de ella,

los que saben de la vida por haber muerto, llaman a esto consejas.

\section{La pérdida del horizonte del encanto}

En Oh, smog (1977) la ciudad como ubre laberíntica prosigue aunque se sientan menos patéticas sus lejanas murallas bordeantes de un centro donde se instala el poeta como un vaticinador del desencanto. Todos los embelesos del vivir diario llegan desde los múltiples horizontes de la sociedad al bardo y éste los conjura en la áspera substantividad de un mundo sin confianza en ese algo escurridizo llamado "bien", a su vez devela la naturaleza de esa realidad signada por el dolor, el tedio, los suicidios, la rutina, la violencia, la imposibilidad del desencuentro (el desencuentro), la picaresca como conducta habitual, la desilusión, la gran soledad, el desaliento. Desciende como una ácida lluvia implacable la mala época sobre su testigo más lúcido en acusarla mediante, paradógicamente, la poesía.

Avanzaré sin sentir asco ni pena ni arrepentimiento largo a largo a tenderme en las gradas de este reino donde el papel higiénico ondea en los palcos de botellas.

Me iré a engordar los límites en que el cují y la rosa se abrazan sin contradecirse y la ciudad está en paz con sus víctimas y no duerme desvelada por el pico de los pájaros ebrios que mis sueños escarban sin prisa y a mis expensas aún no terminan de darse su cena

Avanzaré entre la goma espuma y el anime, entre el poliéster y la fibra entre el vynil y la resina 


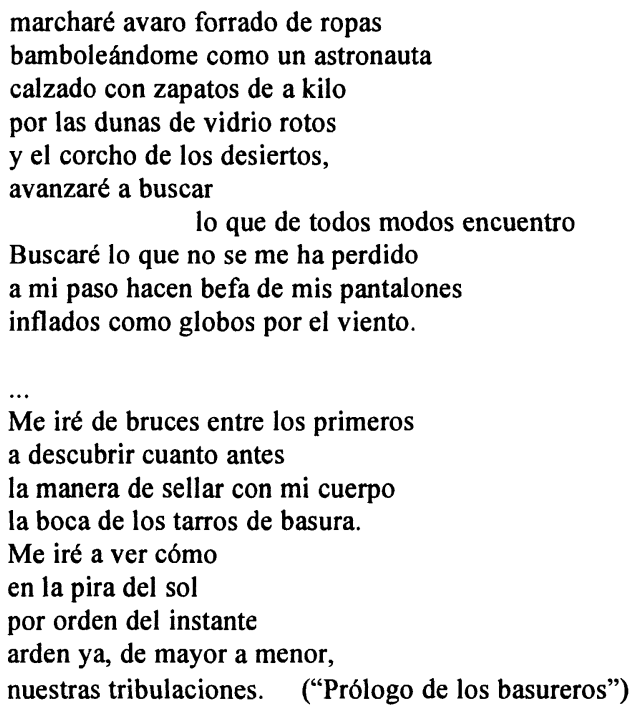

En este poemario Calzadilla la mayor de las veces introdúcese en el texto a través de un actante funcional quien interpreta y "canta" el infortunio y la miseria del hombre consubstanciado con su ciudad en la derrota del espíritu y en la exaltación de la desdicha. La espiral descendente de la historia ética de Venezuela, la cual comenzó en la frustración política colectiva de los años sesenta, halla en Calzadilla un testifidante y fiscal de excepción en el mundo de la poesía y quizás sea $O h$, smog su libro más iluminador al respecto. Por supuesto, en este rol intelectual no va solo, por cuanto ello - testimonio y poesía de acusación epocal - revela un rasgo común en muchos escritores de esa década importante por su tragedia social y su trascendencia en ulteriores años; por lo menos en el verso comparte esta dignificación de la furente estética con Edmundo Aray, Jesús Sanoja Hernández, también Caupolicán Ovalles, entre otros.

La composición «Fábula del desencuentro (Orfeo y Eurídice en la ciudad)» muestra uno de los poemas claves del libro $\mathrm{Oh}$, smog. El poeta revive el mito griego para replantear su universalidad y eternidad aun en nuestros días; la separación final entre Orfeo y su amada, esta vez no por la muerte primero y luego la imposibilidad de escapar del infierno sino porque la ciudad (y su época) se ha autogenerado en laberinto fantasmagórico exterior e interior en el ciudadano, donde el acercamiento más próximo entre los amantes resulta un espejismo, porque lo laberíntico siempre inventa una distancia impedidora de todo encuentro factible. Eurídice y Orfeo no se hallarán jamás por cuanto en el infierno de la urbe-meandro y el tiempo paradojal el amor debe sacrificarse a la angustia, a la duda, al miedo, a la verdad de las calles del caotismo cotidiano. Según los planteamientos de Bronislav Malinowski sobre el mito la tesis órfica calza como anillo al dedo en las búsquedas expresivas líricas de este texto, 
Enfocando en lo que tiene de vivo, el mito no es una explicación destinada a satisfacer una curiosidad científica, sino un relato que hace revivir una realidad original y que responde a una profunda necesidad religiosa, a aspiraciones morales, a coacciones e impertivos de orden social, e incluso a exigencias prácticas ...

Hermosísimo poema de $O h$, smog, del cual apenas se copiarán algunas estrofas:

EL

En la calle, puertas y ventanas

son marcos de espejos

que con sus cuerpos otros llenan de muros

pero donde dejamos de vernos

como si con cada cuerpo

el espejo agotara

su posibilidad de reflejarse

y así, rodeados de gentes,

vamos, vamos solos al desencuentro

que nos une

\section{ELLA}

En la ciudad hasta los nombres propios

inventan un sexo en cada cosa

desde un ojo que se hunde

lentamente en el fango de los gestos

Se llega sólo a donde está el comienzo

Pues sucede que no parece haber principio

ni término si siempre se está en el centro

de la multitud que somos

\section{ELLA}

Ni siquiera en el sueño

nuestros espíritus llevan alas

EL

Las pisadas dejan huellas de ceniza

que nos sujetan a la memoria

de una bella derrota

La cera derretida pone límites

y cede ante un abismo que cae en otro abismo

A medida que corremos hacia nosotros

creemos dar en la certeza de un encuentro

que la distancia cada vez más corta

vuelve a situar en el extremo

de una separación dolorosa

${ }^{1}$ Citado por Mircea Eliade, Mito y realidad (Madrid: Guadarrama, 1973) 32. 
EL

Los que aman arrojan la primera piedra

y desencadenan en ellos mismos

los signos de la primavera

al firmar con sus cuerpos

un pacto de transitoria belleza

Por esto han de sacrificarse

El deletéreo mosaico de la ciudad por donde el bardo desliza su mirada y sus cogitaciones, las calles llenas de podredumbre, los basureros, sus fontanas contaminadas, sus estatuas alejadas de su símbolo por la abulia burocrática, sus árboles y plazas, sus parques abandonados, sus ríos turbios de suciedad, funcionan como el polimorfo escenario donde levántanse las estelas de más de sesenta poemas excelentemente troquelados dentro de una concepción lírica muy personal y en cada caso subyugante. Pese a todo la congoja suspendida y repartida igual para todos como un smog universal en ningún momento contamina la calidad calológica de las estrofas de Calzadilla. Léase, por ejemplo, este poema:

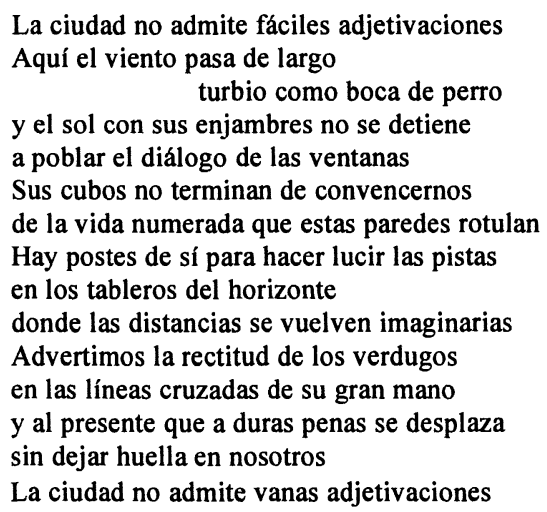

("La ciudad")

\section{El ludismo}

Tal vez la evolución formal, trascendental, de la escritura poética de Calzadilla lo define el perseguir en ella apartarse paulatinamente de lo calológico en sí mismo para apuntar a lo lúdico. Aparece la emoción estética de su lector no sólo en el deleite de la lectura artística sino en la medida como la inteligencia acciona al descifrar las antinomias, los juegos del intelecto, los proloquios, y avanzar en el singular jardín de su lenguaje sembrado de extrañas florescencias lingüísticas. Usa el ludismo de palabras y frases para sumir su pensamiento en muchos aspectos del entorno humano: la existencia misma, la poesía y su escritura, el azar, el encabalgamiento del éxito y del error, el tiempo, el fenómeno de la memoria, el cuerpo y la palabra, el paisaje y la mirada, la alienación y la muerte. Todo ello muy presente, por ejemplo en Tácticas de vigía, opúsculo de 1982, 
donde también riela una constante ensamblada en toda su lírica, ese humor ingenioso y fino.

Al concluir la redacción de su texto levantaba la página escrita y la miraba a contraluz. Verificaba entonces que la transparencia del soporte no dejaba ninguna duda acerca de la inanidad de lo escrito ("Ejercicio de estilo").

Han quedado los funéreos años sesenta atrás en el tiempo aunque su tatuaje está allí, y el "ciudadano sin fin" descarriado en el laberinto trágico de la urbe se ha refugiado en el intenso universo de la palabra. No obstante ambas situaciones han modelado una conducta en ese hombre en permanente estado de alerta, sagaz, suspicaz, existencialmente insomne, dueño de una poesía desencantada y sarcástica, donde el mero interés por lo calológico en sí mismo, como único fin, resultaría sospechoso; la frase entonces se orientará, repito, hacia lo lúdico para desnudar la conciencia y mostrar así otros niveles de la realidad más allá de lo aparente cotidiano al través de inteligentes enlaces imaginativos.

La palabra ha llegado a su madurez

Ahora mismo comienza a envejecer

Para ella ya pasó el tiempo de cosecha

Pronto será incapaz de valerse de sus manos

$\mathrm{Y}$ aun menos de su cabecita estrujada por el tiempo

La declararán inválida. No podrá ir más

a los consejos de familia ni decidirá por sí sola

los pasos que habrá de dar para recuperar

la salud en este siglo de manos. Mientras

habla necesita que le sostengan la voz. Querrá

al menos que la saquen a pasear una vez al mes

Seguramente habrá enfermado porque ahora

la llamo y no responde

O quizás sólo está haciéndose la muerta (“Ciclos”).

Escapa la belleza sin embargo a la alertitud de Calzadilla, su guardia insomne a veces se rinde y deja paso al juglar hedonista del verso, para asentar composiciones de repetable nivel artístico, el bardo traiciona al bardo en nombre de la venustez:

En agosto, cuando el pasto está maduro en el valle, los cuerpos adquieren la consistencia de los frutos, como si el sol les ordenara roturar el cielo con el brillo de una nostalgia que adopta la forma de ellos. Así íbamos, al descampado, sugiriéndole a la naturaleza la imagen de no ser distinto a ella. Y, como el pasto, amábamos fundirnos en incendios, maduros también para sentir que la muerte no nos era ajena. ("Báscula")

\section{Poetología}

Concurren en todos los textos literarios de Calzadilla de una u otra forma conceptuaciones sobre la poesía, sobre la escritura. Emanan de un intelectual quien constantemente interrógase sobre su creación, escribe y medita sobre el acto mismo de 
hacerlo. Calzadilla es un vigilante insomne de su palabra escrita. Y su pensamiento sobre su textualidad lo extiende, lo generaliza, lo trasciende. Inquiere con furia sobre lo escritural literario, y con su acostrumbrada buida lucidez al hueso del hecho poético va, pero por supuesto no por las vías del análisis académico ni de la teoría literaria pura sino por las rutas insólitas del humor, del sarcasmo y, a veces, de la ironía, más no por ello améllase la perspicacia y muestran algunos de sus juicios verdaderos aciertos. Tal vez sus libros donde esto se manifiesta con mayor claridad lo confiesan Una cáscara de cierto espesor, de 1985, y Diario para una poesía mínima, de 1986. De nuevo acá sus composiciones no apuntan a la diana de lo calológico para sí centrarse en agradables especulaciones sobre la vida creativa, poética y artística en general. En el primero de ellos aparece por primera vez, de manera diáfana, el recurso expresivo estético de la ironía en su concepción clásica. El poeta presenta ese juego oscilante de revelación y ocultación, entre lo afirmado por el plano evocado en función de significante (lo escrito) y lo oculto o verdadero siginfidado (sugerido, pertenece al entorno fuera del texto), mediante la sátira el poeta subraya cuanto opaca, origina una atmósfera con ese sabor característico, como cuando dice:

\author{
Tus palabras son torpes para representar. Lo que \\ no es torpe es tu convicción de que las cosas \\ podrían llegar a decirse de modo mejor. \\ En este caso la representación no dependerá \\ tanto de las palabras y del sentimiento \\ como de tu idea de las cosas. \\ Pero si tus sentimientos son confusos; \\ pero si tus ideas son pobres \\ ¿cómo no han de serlas aún más tus palabras? \\ - Sin embargo, los poetas comprueban \\ que el balbuceo tiene sus ventajas.
}

No interesa, pues, ni la autenticidad ni el arte verdadero sino cualquiera fama (la cáscara de cierto espesor) si ello permite escalar en la sociedad. Parecido enfoque irónico de otra composición titulada "El hombre curvo":

La dificultad de mantenerse en una postura bastante recta con respecto a su cuerpo lo privaba de rectitud. Su rectitud, así, pues, era más bien curva, como él mismo.

Hay fura de la estética de la ironía consideraciones muy serias, sin abandonar la sonrisa, sobre poesía como:

Lo real para el poeta es lo nunca visto ("Los grados de lo invisible")

Y su "Poética":

Como el agua del grifo,

Las palabras están ahí, contenidas y listas, 
a punto de salir. Libres pero canalizadas.

Así el poema.

O sobre el arte en sí mismo:

El arte no es el único conocimiento cuya teoría

se confunde con su práctica. Pero sí el único

que tiene que ver exclusivamente con el goce

de su propio conocimiento.

("De cuerpo entero, 9")

Mas en verdad predomina en este inteligente opúsculo el ácido uso de los satírico y lo sarcástico en la materia general ya anunciada, poesía y arte. He aquí dos muestras donde el texto, sobre ese particular, su clímax alcanza:

Los libros que

a los vasos con whisky

servían de pedestales ("Haikú a propósito del bautizo un libro de versos en Caracas")

Un reloj ablandado sobre un desierto duro

Una jirafa en llamas bajo el cielo macerado

Sólo falta a este escenario surrealista

Un bufón con los bolsillos llenos

Pero entonces ¿quién va a ocuparse de pintar el cuadro? ("Dali”)

Pese a haber transcurrido apenas un año del libro anterior cuando se edita Diario para una poesía mínima y aunque las preocupaciones poetológicas y artísticas se sostienen sin embargo el lenguaje se ha tornado más sereno, lo sarcástico y lo satírico asordínanse, se asutilan y se colocan bajo un orden expresivo más tradicional, menos osado en su desfachatez y más audaz en no temer descubrir Calzadilla su talento de gran poeta lírico.

Observa con qué facilidad escribes

sobre pájaros. Pero ¿cuántos has palpado

amorosamente con el calor de tus manos?

¿Cuántos han latido realmente

bajo la presión de tus dedos?

¿Acaso los has descrito

sin olvidar detalles como quien

conoce bien su cuerpo amado?

¿Los has liberado acaso

del peso de tus palabras?

(“Cantar de los pájaros”)

Hermoso opúsculo éste de Calzadilla, dueño de una escritura sosegada, henchido de inquirimientos sobre el hombre como epicentro de su compleja circunstancia, sin dejar de dedicarle una buena parcela a la vida poética y artística: 


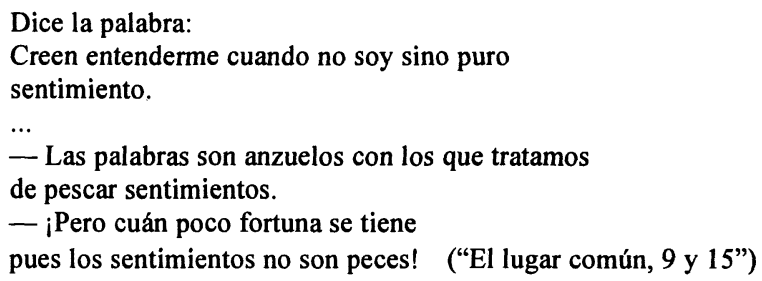

\section{La tragedia de la comedia cotidiana}

Osténtase a lo largo de toda la obra poética de Calzadilla hasta el presente unos rasgos estilísticos presistentes los cuales contribuyen a hondar la huella original de su producción. Revelan estos estilemas su tendencia a la construcción aforística y el jugar con las frases hechas, tomadas del hablar corriente venezolano, y a partir de las cuales despliega sus composiciones. Pero en Agendario. Cuerpos escritos, de 1988, ello se intensifica de manera patética. Libro muy bien concebido, y como su título lo indica, los textos descansan sobre una agenda real, día a día, acompañados de bosques de cuerpos de mujeres y hombres desnudos. Nada más apropiado para escribir sobre lo grotesco de la vida corriente como una agenda, por eso resulta en cierto modo un mirar airado desde la ventana de la sátira lo burlesco del humano deambular cotidiano, acentuados por los dibujos algo goyescos los cuales aunque no se enlazan temáticamente con los textos alimentan esa atmósfera grotesca, donde las personas y sus circunstancias preséntanse dislocadas, descoyuntadas, no armónicas en el concepto tradicional del como debe ser el vivir. Expuesto todo lo anterior en sus composiciones de estructura, casi siempre, aforística, sentencias breves producto de una contemplación irónica y satírica de la comedia del existir habitual de la gente en el meandro de la urbe para sentar un doctrinal de la absurdidad de la vida ordinaria.

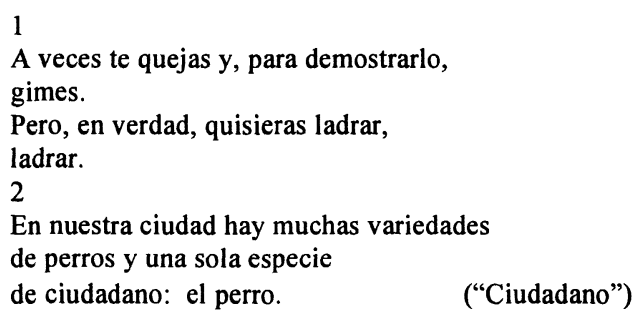

No proviene su conexión con la cotidianidad meramente de lo conceptual sino el poeta se introduce a través del lenguaje, toma como puentes frases hechas, metáforas fosilizadas dimanantes del común decir de las personas, como éstas: "Que la palabra vaya adelante"; "sin pérdida de tiempo"; "se adelantaba a los hechos"; "saber a qué atenerse"; "lleva el mundo a cuestas"; "meterme ... en un bolsillo"; "dar ese paso"; "nos lleva varios puntos de ventaja"; "aceptaría de buena gana"; "llevas la soga al cuello"; "como si tal cosa"; "el 
tiempo es largo/la vida corta"; "estar a la altura de las circunstancias"; "piedra de toque", etc.

$$
\begin{gathered}
\text { - Si no puedes estar a la altura } \\
\text { de las circunstancias, } \\
\text { al menos ponte a la altura de } \\
\text { tu dignidad. } \\
\text { - Pero si mi dignidad está } \\
\text { casi a ras } \\
\text { del suelo, }
\end{gathered}
$$

respondió el gusano.
(“Diálogo")

El humor subterráneo de lo grotesco en Agendario no mueve a risa sino inquieta, o como dice Wolfang Kayser en su Interpretación y análisis de la obra literaria,

... y la risa que nos causan las deformaciones y los descoyuntamientos va siempre mezclada con cierto horror. El sentimiento que lo grotesco nos inspira no es el miedo a la muerte, sino el temor a la vida, y la creación artística es aquí como un intento de conjurar y exorcizar lo demoníaco-abismal. ${ }^{2}$

En el fondo no significa otra cosa sino la prolongación en este Agendario de la noción del "ciudadano sin fin" de Calzadilla y sus imbricacinoes con lo artístico y la poesía de la configuración de la paradoja y del laberinto, todo ello cristalizado desde los años sesenta $\mathrm{y}$ fortalecido por la vividura frustrante y agobiante de la Venezuela posterior.

$$
\begin{gathered}
\text { Una poesía de la tribu escrita con palabras urbanas } \\
\text { como parodia del esfuerzo } \\
\text { que los habitantes hacemos } \\
\text { para merecernos la capitulación } \\
\text { que la ciudad nos brinda } \\
\text { más que como expresión de conformidad } \\
\text { con el hecho de que } \\
\text { la guerra que la ciudad nos hace } \\
\text { no nos la merecemos. }
\end{gathered}
$$

("Nostalgia de los 60")

\section{El humor}

Ocupa el humorismo en la literatura un nivel de entusiasmo equivalente a la poesía. En ambos el lenguaje una sublime complejidad adquiere hasta alcanzar tal grado de sutileza capaz de despertar en el lector/oidor esa exaltación sin nombre en el caso de la poesía, o esa rutilante emoción cuya expresión de inteligencia la define la sonrisa, raras veces la carcajada, el humor. Tratamiento, en ambos casos, muy especial del ludismo de las palabras para tocar con ellas la zona-misterio del alma donde anida el sobrecogimiento

\footnotetext{
${ }^{2}$ Segunda edición (Madrid: Gredos, 1958) 615.
} 
(para la poesía) o el locus donde mézclanse el ingenio y el júbilo asordinado cuyo rostro lo encarna la sonrisa. Juan Calzadilla con su opúsculo Diarios. Aproximaciones a un decir siempre aplazado, de 1990, ciñe ese difícil espacio de la expresión literaria. Allí la poesía no apunta a la belleza pura sino hacia la gracia, la agudeza, lo ameno del escribir para envolver con las frases conceptuaciones encarriladas hacia latitudes profundas más allá de la aparente realidad de cuanto se suele entender por existencia, muerte, arte plástico, poesía y poética, la objetividad, el tiempo, las pasiones, etcétera. Todo este pensar encauzado por los rieles del humor pulcro, elegante, lastrado con proporcionales dosis de escepticismo, lejos de cualquier tosquedad y sí apoyado en un hondo sedimento humanístico, como al fin y al cabo debe corresponder a un vate muy exigente siempre consigo mismo y con su entorno intelectual.

El cero justifica que nos hagamos de él una imagen redonda.

Pero la representación exterior no basta para saber qué hay en su interior.

Necesitamos que los bolsillos nos lo expliquen para poder creer que no contiene nada. ("Balance")

O sobre la pintura:

¡Qué tontería más grande!

La retrospectiva de un pintor viviente. Como

si esto pusiera término a su obra. Ahora es

cuando tendría que seguir pintando para demostrar

que la pintura ya había muerto mucho antes.

(El arte es innovación, no conocimiento. Por

eso no tiene memoria de sí). ("Viendo una retrospectiva")

O en torno a la muerte:

La lección más sabia que el hombre recibe a diario: ¡La muerte! Y sin embargo, por nada del mundo se la aprende. Debería sabérsela de memoria, pero vean: Asiste a los entierros como si tal cosa! ("Un entierro")

Y presente como una pátina muy fina sobre su humor, el escepticismo,

En términos actuales, el escepticismo puede considerarse como el optimismo de la derrota.

\section{Lo lírico}

Como se ha dicho repetidas veces a lo largo de este pequeño ensayo de crítica literaria, detrás del desenfado escritural, del humor filoso, del sarcasmo, de la ironía 
envuelta en estructura aforística, de lo satírico, en Juan Calzadilla se oculta/revela un gran lírico. Hay en todos sus libros muestras suficientes para probar la calada de la sentimentalidad de Calzadilla y su alto respeto por la belleza del poema. No se exhibe, por supuesto, como un prisionero de la busca de lo calológico por sí mismo, pero en sus composiciones lo lírico reclama también su dimensión para depositar en ella la sorpresa de avivar el espíritu por el sobrecogimiento de lo bello, compartido, valga la repetición, con el placer del fino humor, del recurso expresivo artístico de la ironía, del sabor de accionar la inteligencia mediante el aforismo, del pensamiento agudo sobre el fenómeno creativo. No obstante sus libros más líricos lo representan Tema para el próximo silbido, de 1991, y Curso corriente. Máximas y mínimas, de 1992. Versos alternados con prosa sugerente, sermo nobilis, levantados sobre vivencias, experiencias, recuerdos, reflexiones, reconocimientos, donde palpita la madurez del bardo, acendrada sabiduría. Léase este poema del primero de los libros citados:

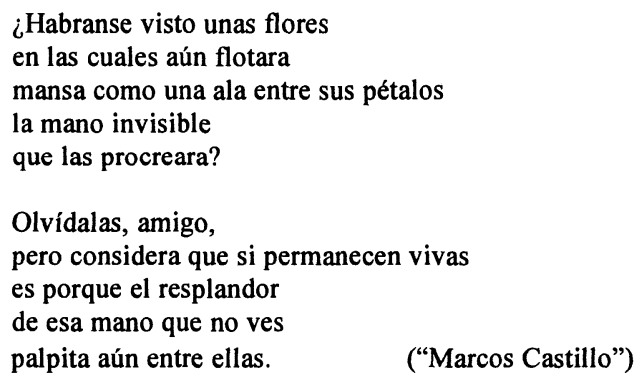

Compártese esta presencia en Curso corriente con una selección de aforismos donde el pensamiento de Calzadilla pasa revista a múltiples aspectos conceptuales diseminados a lo largo de su profusa producción poética, mucho de ellos suficientemente puntualizados en el presente trabajo. Mas en este item se trata de poner en primer plano lo lírico y por eso se eligió en este opúsculo su poema “¿En dónde reside la grandeza de Emily?”:

En su jardín.

en el asombro menudo de las hojas, en los charcos con sapitos y légamo, en las azucenas y en la alondra, en la abeja dactilógrafa y hasta en una mosca espiando por el vidrio de su ventana. Del mármol no le hablen. Por éste sentía repulsión. Lo empleó contadas veces como cuando a Amherst llegaron soldados del Norte y ella, para mostrar que estaba agradecida, se imaginó tallada cual doncella de Orléans simulando en el mármol unos labios para siempre sonrientes. 


\section{Final}

Entre los poetas de su generación Juan Calzadilla ofrece una obra bien estructurada, sostenida por una lúcida concepción de lo artístico y de lo literario. Pocos como él han dedicado tanto pensamiento a la fenomenología de la creación poética comunicada en sus mismos textos líricos, aforísticos, testimoniales; y define este rasgo uno de los horizontes semánticos de su saber escritural y lo deslinda de sus contemporáneos; buena parte del tributo conceptual de sus libros pertenece a lo llamado por Aristóteles en su Metafisica "el pensar poiético", un meditar sobre la inventiva intelectual y artística en particular, en el caso de Calzadilla una poética capaz de pensarse a sí misma.

Calzadilla posee una valentía de lenguaje poco común entre los bardos del sesenta. Reflexionador profundo sobre el compromiso de vivir, sobre la difícil tarea de exponer la verdad, de lanzarse abroquelado con su arrojo al centro de la arena en el juego de la existencia y actuar con grandeza y desparpajo, sin miedo ni a los otros ni a eso aun más terrible por su complejidad y su misterio: la palabra. Dignifica Juan Calzadilla con suficiente nivel estético, aportativo y de autenticidad, la poesía actual venezolana y latinoamericana.

La poesía es el único género que solicita que cuanto se diga acerca de ella sea también poesía. De este modo lo que se dice sobre el poema es el poema mismo.

Así es la vida. ${ }^{3}$

${ }^{3}$ J. Calzadilla, Curso corriente. Máximas y mínimas (Caracas: Fondo Editorial Tropykos, 1992) 76. 